\title{
Paediatric Virology in the Hippocratic Corpus (Review)
}

\author{
IOANNIS N. MAMMAS and DEMETRIOS A. SPANDIDOS \\ Department of Clinical Virology, School of Medicine, University of Crete, Heraklion 71003, Greece
}

Received March 24, 2016; Accepted May 23, 2016

DOI: $10.3892 /$ etm.2016.3420

\begin{abstract}
Hippocrates (Island of Kos, 460 B.C.-Larissa, 370 B.C.) is the founder of the most famous Medical School of the classical antiquity. In acknowledgement of his pioneering contribution to the new scientific field of Paediatric Virology, this article provides a systematic analysis of the Hippocratic Corpus, with particular focus on viral infections predominating in neonates and children. A mumps epidemic, affecting the island of Thasos in the 5th century B.C., is described in detail. 'Herpes', a medical term derived from the ancient Greek word 'ع̋ $\varrho \pi \varepsilon v$ ', meaning 'to creep' or 'crawl', is used to describe the spreading of cutaneous lesions in both childhood and adulthood. Cases of children with exanthema 'resembling mosquito bites' are presented in reference to varicella or smallpox infection. A variety of upper and lower respiratory tract viral infections are described with impressive accuracy, including rhinitis, pharyngitis, tonsillitis, laryngitis, bronchiolitis and bronchitis. The 'cough of Perinthos' epidemic, an influenza-like outbreak in the 5th century B.C., is also recorded and several cases complicated with pneumonia or fatal outcomes are discussed. Hippocrates, moreover, describes conjunctivitis, otitis, lymphadenitis, meningoencephalitis, febrile convulsions, gastroenteritis, hepatitis, poliomyelitis and skin warts, along with proposed treatment directions. Almost 2,400 years later, Hippocrates' systematic approach and methodical innovations can inspire paediatric trainees and future Paediatric Virology subspecialists.
\end{abstract}

\section{Contents}

1. Introduction

2. General principles

3. Viral infections in neonates and children

4. Conclusion

Correspondence to: Professor Demetrios A. Spandidos, Department of Clinical Virology, School of Medicine, University of Crete, Heraklion 71003, Greece

E-mail: spandidos@spandidos.gr

Key words: Paediatric Virology, viral infections, children, Hippocrates, Hippocratic Corpus

\section{Introduction}

Hippocrates (Fig. 1), one of the most outstanding physicians in the history of Medicine, is considered as the principal author of the Hippocratic Corpus (1-65). Born in the island of Kos around the year 460 B.C., he founded the Hippocratic School of Medicine, the most famous Medical School of the classical antiquity, located in his birthplace. His collection of Books (1-65), entitled by subsequent researchers and librarians as the Hippocratic Corpus, consists of $>65$ ancient Greek medical studies closely linked with the teachings of Hippocrates and his disciples. This collection of notes, lectures and case reports was gathered, compiled and preserved at the ancient library of Alexandria during the Hellenistic era in the middle of the 3rd century B.C. This was the first extensively written worldwide effort in Medicine (66) to document the clinical practice of that time with regards to various diseases, including viral infections in neonates and children.

Since Homer's Iliad, written sources on medical practice in ancient Greece can be found in classical literature, including tragedies, comedies and philosophical texts from the 6th to the 5th century B.C. Moreover, in Greek mythology, we find several references to physicians and surgeons, such as Centaur Chiron. Chiron, often portrayed as the first neonatologist of the Mediterranean world, treated inside his cave the preterm baby Asclepius, son of Apollo, who was born by the first recorded caesarean section (67). In comparison with all other ancient Greek sources, the Hippocratic Corpus represents the first methodically rigorous and documented systematic approach in the history of Medicine.

Recently, Hippocrates' early contribution to the new scientific field of Paediatric Virology was highlighted in the Workshop on Paediatric Virology held in Athens, Greece, on the 10th October, $2015(68,69)$. This Workshop was organized under the aegis of the 20th World Congress on Advances in Oncology and the 18th International Symposium on Molecular Medicine, with $>500$ participants from all five continents. The aim of our article was to perform a systematic analysis of the Hippocratic Corpus with the aim of documenting specific references by Hippocrates to viral infections common among neonates and children. Bacterial infections fall out of the scope of this review; we have also excluded references to cases relating purely to adults.

\section{General principles}

Hippocrates' famous dictum 'prevention is better than cure' offers a valuable principle for Preventive Medicine, including 
Paediatrics, and provides the milestone of all immunization strategies used today in neonates, children and adolescents. In the Book Epidemics I (51), we read Hippocrates' fundamental instruction to physicians 'to do good, or to do no harm', a principle of great value, which should guide the management of all diseases, including viral infections. According to the Hippocratic Oath (1), physicians' aim should be to use treatment 'for the good of their patients according to their ability and their judgment, but never to harm or do wrong to them'. The medical encounter consists of three parts: the disease, the patient and the doctor (51). The patient is given by Hippocrates an equal role with the physician as collaborators in the battle with the disease (51). Humanitarianism is considered more than valuable for the practice of the art of Medicine (7).

Although there is no book in the Hippocratic Corpus dedicated solely to paediatric viral infectious diseases, there are several descriptions of references to viral infections occurring in neonates and children, along with proposed management approaches and treatment directions (70). Despite considerable differences in the explanations of the diseases presented by Hippocrates, there is no doubt that the medical terms used relate to what we now recognize as viral infections. Infectious diseases, such as otitis, mumps, gastroenteritis, hepatitis and meningoencephalitis, are described with impressive accuracy. Other terms, such herpes, herpangina, opthalmia and dysenteritis, are also encountered; however, these are not used to refer to the same conditions in their modern usage. Details of specific epidemics are given, while Hippocrates' efforts to correlate them with 'weather changes' (51-57) reminds us of Hippocrates' desire to discover their hidden aetiology (71). Interestingly, in several sites of the Hippocratic Corpus, we detect Hippocrates' encouragement to physicians to detect the 'causes' of each disease $(15,52,56)$. According to Hippocrates, diseases are the result of an imbalance in the constituents of the body, referred to as 'humors' $(58,62)$. Different pathophysiological mechanisms and directions for treatment are provided for several diseases, while the valuable therapeutic role of diet and dietary measures has been expressly highlighted $(5,27-30)$. In the Books Aphorisms, On Airs and Epidemics VI $(8,15,56)$, we also read Hippocrates' general principle that 'opposites cure opposites'.

\section{Viral infections in neonates and children}

Mumps. Parotitis is one of the most accurately described viral infectious diseases in the Hippocratic Corpus. In the First Constitution described in the Book Epidemics I (51), we find an impressively precise description of the disease in reference to an epidemic of mumps that occurred in the island of Thasos in the 5th century B.C. After a detailed reference to the climatic conditions that prevailed during the different seasons on the island, the author describes an epidemic with fever, 'formations by the ears on one side for many and on both sides for most', dry coughs and hoarse voices, occurring during the early spring. These clear and easily recognizable symptoms 'happened to children' and 'mostly to those, who were engaged in the exercises of the palaestra and gymnasium'. The final outcome of 'the inflammation with pain, which occurred sometimes in one of the testicles and sometimes in both' makes the diagnosis of an outbreak of mumps very clear.

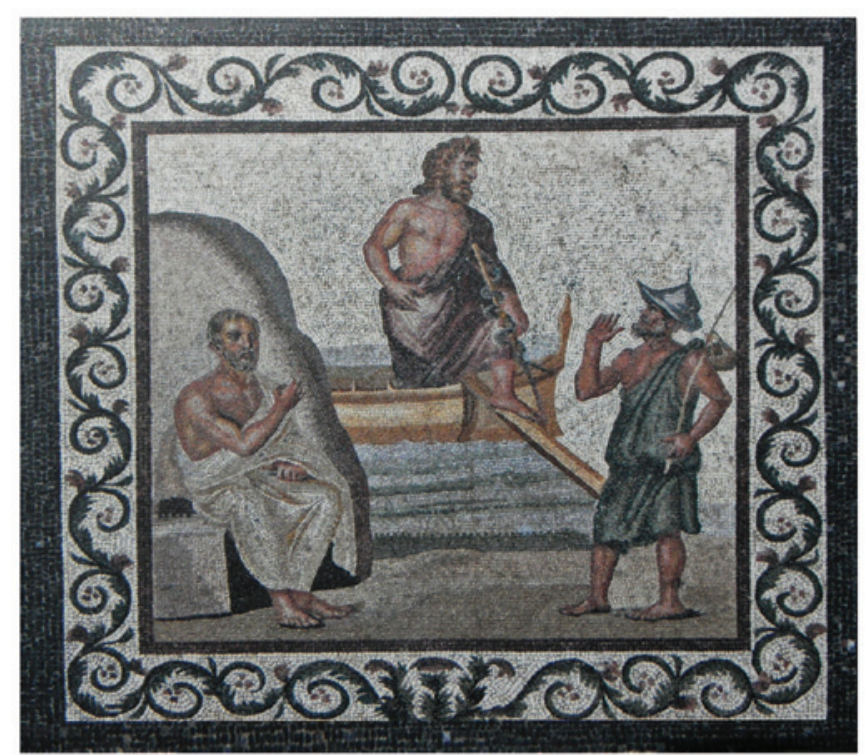

Figure 1. The mosaic of Hippocrates and Asclepius made of colourful stone tiles (3rd century A.D.). In the center, Asclepius, the ancient Greek God of Medicine, arrives on the island of Kos by boat, holding his snake-entwined Rod. He is greeted by a hospitable local inhabitant to the right, while the physician Hippocrates sits dressed in white on the left (from the Archaeological Museum of Kos, Island of Kos, Greece).

This is the first written description of mumps complicated by orchitis that we encounter in the history of Medicine and one of the easiest cases to diagnose (70,72). Although Hippocrates does not use the term parotitis, he describes 'formations by the ears'. This is clearly a reference to mumps, whose symptoms include swollen salivary glands with a secondary severe sore throat, fever, headache and swollen testicles in approximately twenty percent of post-pubescent males. Mumps is transmitted through saliva droplets, and therefore it makes sense that it would be easily spread, while boys and men exercise and wrestle. Interestingly, Hippocrates describes in detail the weather conditions during this epidemic in an attempt to find the cause of this condition. Moreover, he places great emphasis on the value of observation in relation to the disease process, while he tries to perform interesting epidemiological observations, such as correlation with age, gender and occupation.

The term ' $\tau \grave{\alpha} \pi \alpha \varrho \grave{~} \tau \hat{\alpha} \hat{\omega} \tau \alpha$ ' (ta para ta ota), meaning 'formations by the ears', is also used is several other sites in the Hippocratic Corpus, including the Books Prorhhetics I, Coan Prenotions, On Crises, Epidemics I, Epidemics II, Epidemics V, Epidemics VI and Epidemics VII (10,12,16,51,52,55-57). However, in each case it is not clear whether this term is used to describe swelling of parotid tissue or lymphadenitis. The possible association between the upper respiratory tract symptoms and the development of orchitis is also referred to in the Books Epidemics I, Epidemics II and Epidemics IV $(51,52,54)$.

Herpes. The term '๕̌อлทร' (herpis), meaning 'herpes', has been used for $>25$ centuries to describe spreading, usually ulcerative, cutaneous lesions, occurring in both childhood and adulthood (73). In the Hippocratic Corpus, this term, derived from the ancient Greek verb 'ह̋лเv' (herpein), meaning to 'creep' or 'crawl' in reference to the spreading nature of the herpetic 
lesions, is mentioned in $>5$ locations $(8,11,12,31,53)$. In the Book

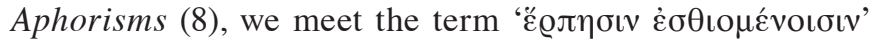
(herpisin esthiomenisin) to describe 'severe herpes' affecting the anus, genitalia, uterus and bladder. The same term is also used in the Book On Use of Liquids (31), where we read that using warm water baths is valuable for several skin disorders, including 'severe herpes'. In the Book Epidemics III (53), there

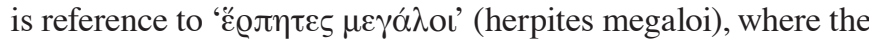

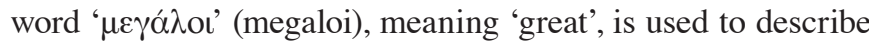
the severity and not the size of the described lesions. The usage of the word in the Books Prorrhetics II (11) and Coan Prenotions (12), which are thought to have been written before Hippocrates, indicate the usage of this term prior to the 5 th century B.C. In the Book Prorrhetics II (11), we encounter the

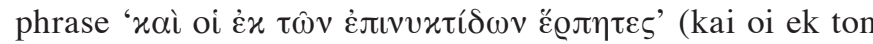
epiniktidon herpites), probably used to describe 'herpes with dark color', occurring in patients up to the age of 60 years, while later on we read that 'herpes' is less dangerous than cancer, but harder to cure. In the Book Coan Prenotions (12), Hippocrates describes a type of herpes, which starts above the groin and spreads towards the flank and the groin, indicating 'a disordered state of the abdomen'.

Although the last condition can be attributed to herpes zoster infection, it is interesting that shingles - derived from the Latin word 'cingulus', meaning 'belt', referring to the most common site of emergence along peripheral nerves of the back that wrap around the abdomen - are not recognizably described any where else in the Hippocratic Corpus. Moreover, nowhere in the Hippocratic Corpus do we come across the modern Greek term for shingles, 'herpes zoster', derived from the Greek word for 'girdle'. However, it is questionable whether the lesions described in the previous locations refer to herpes simplex virusassociated lesions or to a much wider range of skin disorders, including cutaneous tuberculosis, erysipelas, dermatophytosis, eczema, smallpox and skin carcinoma. Indeed, in most of these conditions, the epithet 'creeping' is far more apposite than it is to the conditions, which we know, today, as herpes. As noted by Beswick (73), the term is used to describe a type of lesion rather than a specific disease. Moreover, the original meaning seems to have changed considerably over the years. Possibly none of the conditions, which we designate as herpes today, would have been called that in Hippocrates' time, although the word itself was already well known as a medical term.

Moreover, in the Book Epidemics VI (56), we read about the presence of ulcerations on the lips in intermittent fevers.

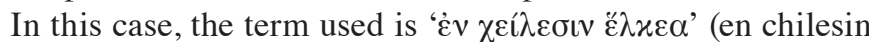
elkea), meaning 'ulcers on the lips', reminding us of the simple HSV-1 herpes lesions (herpes febrilis). In the Book Aphorisms (8), it is well specified that ulcers on the lips occur frequently during the summer months. In the Book $O n$ Humors (14), we find a reference to the co-existence of ulcers in the mouth and the genitalia. Other terms used with similar meaning are ' $\alpha \phi \theta \omega \delta \delta \varepsilon$ ' (aphthodea) and ' $\alpha \phi \theta \alpha \iota$ ' (aphthe), meaning 'aphthous ulcers'; however there is no explanation for the different usage of each term $(8,12,34,53)$. In the Book Nature of Women (34), the occurence of aphthae is described in children's genitalia, suggesting genital herpetic lesions caused by HSV, where a specific treatment - "crush almonds and bull marrow, boil in water, add a little flour; smear over the genitals and inject with water of myrtles' - is recommended.
Varicella-smallpox. In the Book Epidemics VII (57), we read about the case of a child presenting an exanthema, which is described as 'resembling mosquito bites'. Interestingly, the description of this rash states that it 'resembled', rather than was caused by mosquito bites, referring to an exanthematous disease occurring in children. A similar case - it could be the same, since the recorded names of the children's father are strikingly similar (Ephronos versus Ephranonos) - is also mentioned in the Book Epidemics V (55), where it is explained that this exanthema was accompanied by fever and its duration was limited. Moreover, by the sequence of the other reported cases, it can be assumed that this particular case occurred during the 'cough of Perinthos' epidemic.

In the Book Coan Prenotions (12), we come across another reference to the presence of exanthema, again described as 'resembling mosquito bites', and this coexisted with dacryorrhea, abdominal discomfort and nausea. These lesions described in all the above cases could be attributed to varicella virus, although several other infections, such as smallpox, which was widespread at that time, can also be included in the differential diagnosis. However, the absence of a more detailed description of the exanthema - e.g., presence of watery pustules, anatomical location - as well as the lack of any reference to coexisting symptoms, such as itching - prevent us from a precise diagnosis. In the Book Epidemics II (52), non-itching exanthema 'resembling mosquito bites' was found in patients with fever on the 7th, 8th and 9th days of their disease, which was not fatal. Interestingly, the exanthema in this case was palpable as it was described as ' $x \varepsilon \gamma \chi \varrho \omega ́ \delta \varepsilon \alpha$ ' (keghrodea), meaning that it was 'similar to millet'. The same description about an exanthema 'resembling mosquito bites' associated with fever is also used in the Book Epidemics VII (57), where the patient recovered on the 18th day; no precise diagnosis can be achieved in these cases, either. No further information on varicella could be found in any other site in the Hippocratic Corpus.

Skin warts. According to the Hippocratic Corpus, skin warts - which $>40$ years ago were proved to be the result of skin HPV infection - occur frequently in older children and young adults (8). The term used in the Book Aphorisms (8) is

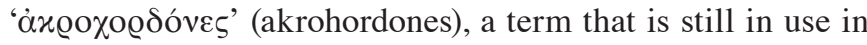
the modern Greek language. Hippocrates also uses the term ' $\mu v \varrho \mu \eta x i ́ \alpha '$ (mirmikia) to describe skin warts (32). For the management of skin warts, Hippocrates recommended vinegar. Interestingly, he uses the verb ' $\alpha \pi \alpha \lambda u ́ v \omega$ ' (apalino), meaning to 'soften' or 'relieve' and not to treat, and wisely avoids giving any recommendation for their cure (74).

Conjunctivitis. Several cases of 'o $\phi \theta \alpha \lambda \mu \iota \alpha$ ' (ophthalmia), the Hippocratic term used for conjunctivitis, commonly attributed to viral infections, such as adenoviruses, are described in the Hippocratic Corpus $(3,8,9,11,13,32,51,53,54,56-58)$; indeed a whole study, the Book On Vision (18), is dedicated to eye disorders. Conjunctivitis is highly contagious, and although there is no specific reference to the modes of its transmission, it is clearly stated that it can become epidemic $(9,56)$, occurring frequently during the summer months (8). It is usually a self-treated benign disease, which is not fatal unless complications develop $(9,58)$. Despite the difficulty in differentiating viral, bacterial, parasitic and allergic causes, conjunctivitis is commonly accompanied 
by pain, eye discharge, dacryorrhoea and oedema, or with the presence of pus $(11,21,51,56)$. The presence of pus in the eyes is referred to as invasive to inner eye formations causing the production of ' $\varepsilon \grave{\lambda} x \varepsilon \alpha$ ' (elkea), meaning ulcers (11). Conjunctivitis can affect only one eye or can be bilateral, affecting both eyes (54). Bilateral conjunctivitis is associated with an increased risk of ulcer formation $(3,54)$. Different management strategies are proposed for the relief of the symptoms, including 'phlebotomy', creams and eyedrops $(8,32,52)$.

Upper respiratory tract infections. Viral-induced upper respiratory tract infections can be inferred through several descriptions of symptoms in the Hippocratic Corpus. These symptoms, including ' $x o ́ \varrho v \zeta \alpha \iota '$ (corize), meaning 'coryzal symptoms',

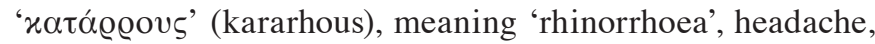
hoarse voice and hoarse wheezing, occur frequently during the winter, as well as the spring months $(3,8,24,32,52,53,55-57,62)$. Coryzal symptoms and rhinorrhoea can be accompanied by fever, headache and cough $(8,56,57)$. In the Book On Ancient Medicine (3), we read that coryzal symptoms are characterized by the presence of increased nasal secretions that can cause nasal ulcers and are caused by the 'cold' as well as other factors. Hoarse voice and hoarse wheezing $(52,53)$ can be linked to laryngitis. Different regimes for the management of rhinorrhoea and headache are found in the Books On Women's I and On Affections $(32,62)$.

Pharyngitis. Pharyngitis, described as ' $\phi \alpha ́ \varrho v \gamma \gamma o s$ $\phi \lambda \varepsilon \gamma \mu$ ov the pharynx', is found in several places $(52,54,56,62)$ in the Hippocratic Corpus. In the Book Epidemics II (52), we read the case report of Scopas, who developed inflammation of the pharynx accompanied by rhinorrhoea and fever. The same term is also met in Epidemics $I V$, Epidemics VI and On Affections $(54,56,62)$. Pharyngeal pain, pharyngeal oedema, pharyngeal irritation, pharyngeal ulcers and pharyngeal harshness are well-documented symptoms and signs, indicating pharyngitis $(10,12,51-53)$. Pharyngitis can be observed either as a primary disease or can coexist with other benign or complicated diseases. Interestingly, in the Book On Affections (62), we find detailed recommendations on the management of pharyngeal inflammation; however, these recommendations are more relevant to the management of tonsillitis rather than pharyngitis. The recommendations for the management of pharyngitis, found in the Book Epidemics II (52), are similar to those proposed for the management of fever in the same study.

Tonsillitis. The anatomy of tonsils is described well in the Book On Glands (21), in the section dedicated to neck glands. Tonsils can become inflammated in association with lymphadenitis (21)

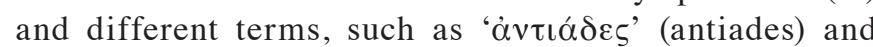
' $\pi \alpha \varrho i ́ \sigma \theta \mu \iota \alpha$ ' (paristhmia) are used to describe tonsillitis caused by several agents, including viruses $(8,21,41,59)$. The second term ' $\pi \alpha \varrho i ́ \sigma \theta \mu \iota \alpha$ ' (paristhmia) is also used for bacterial tonsillitis, as indicated in the Book On Dentition (41), in cases reminding us of diphtheria caused by corynebacteria - 'arachnoid formations' in the tonsils - and 'rheumatoid' fever. In the Book Aphorisms (8), it is well documented that tonsillitis occurs frequently in older children. The risk of the formation of ulcers in the tonsils of children with tonsillitis is documented, a complication which can be risky for the patient (41). This complication occurs when cough and fever coexist, while the presence of tonsillar ulcers in children without fever or with limited clinical course of $<5-6$ days is less frequent (41). In the Book On Diseases II (59), we read the observation of self-healing in some tonsillitis cases. Interestingly, in the Book On Affections (62), we find detailed recommendations on the management of tonsillitis and peritonsillar abscess formation, including ' $\gamma \alpha \varrho \gamma \alpha \varrho i ́ \zeta \varepsilon v v^{\prime}$

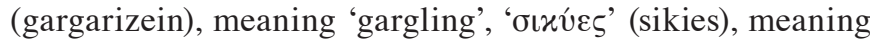
'suction cupping' and surgical management.

Lymphadenitis. In the Book Aphorisms (8), we meet two terms,

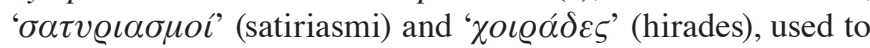
describe 'lymphadenitis' occurring in older children close to the ears area and neck, respectively. The second term is also found in the Books Prorrhetics II and On Affections (11,62), where it is stated that 'hirades' occur frequently in childhood and are treated easily. In the case report of Kallimedontas described in the Books Epidemics V and Epidemics VI $(55,56)$, we find the term ' $\phi u ́ \mu \alpha \tau \alpha$ ' (fimata), meaning 'formations', used to describe palpable masses in the neck, referring to neck lymphadenitis. In Epidemics VI (56), we read that the development of lymphadenitis in case of a febrile disease leads to its 'crisis'. In the Book Prorrhetics II (11), we find a reference to 'purulent' lymph nodes, referring to the complication of inflamed lymph nodes.

Herpangina. Hippocratic ' $x v v \alpha ́ \gamma \chi \eta$ ' (kynaghi), meaning 'herpangina', is a severe disease, accompanied by sore throat, dysphagia, dyskataposia, headache, nasal speech, difficulty in breathing, orthopnoea, lymphadenitis and fever $(8,9,52,55,56,58,59)$. Herpangina can also be associated with vertebral translocation occurring in the cervical spine (52). In all the cases of herpangina, emphasis is given to the severity of the presenting symptomatology involving the upper respiratory tract. Interestingly, we find the discrimination of different types of herpangina based on the presented symptoms $(59,60)$, while the term ' $\pi \alpha \varrho \alpha x v v \alpha ́ \gamma \chi \eta v '$ (parakinaghi), meaning 'para-herpangina', is used to describe milder symptomatology (60). In the Book On Regimen in Acute Diseases (28), we read about the pathophysiology of herpangina, involving the 'increased production of sputum secretions' and the r 'downward movement' from the head to the chest.

Keeping in mind that during the historical period of the second half of the 5th century B.C. several bacterial infections, including diphtheria, were emerging, it is not clear whether a distinction is made in the writings of Hippocrates on the differential diagnosis between viral and bacterial URTI or different types of bacterial URTI. The same term is also used to describe cases presented during the 'cough of Perinthos' epidemic, where herpangina was accompanied by cough $(14,52,55,56)$.

The clinical course of herpangina is acute and severe, having in several cases a fatal outcome $(58,60)$. In the Book On Diseases III (60), we read that herpangina can be fatal in 5, 7 or 9 days. In cases with herpangina, the presence of pleuritic pain and orthopnoea are considered to be negative prognostic signs leading to death (9). Headache, productive cough and 'violent' coughing are three other symptoms with negative prognostic value among patients with herpangina (12). In the Book Aphorisms (8), it is well documented that in patients with 
herpangina the complication of pneumonia can be fatal, with a proposed survival of 7 days. On the other hand, the presence of external neck swelling - possibly indicating lymphadenitis - is a positive prognostic factor in cases with herpangina (8).

Different strategies are described for the management of different types of herpangina, including 'phlebotomy' $(28,52,65)$, ointments with rosemary, wild raisin, absinthe, 'elatirion' and honey (32) and inhalations with vinegar, nitro, oregano, cardamom, hyssop of Cilicia, sulphur and tar $(59,60)$.

Lower respiratory tract infections. Viral-induced bronchiolitis and bronchitis, presenting with cough accompanied by gastrointestinal disorders, occur frequently in neonates and children $(8,54)$. The symptom of ' $\beta \eta$ ' $\xi$ ' (vix), meaning 'cough', predominates during the winter; however, several cases are also observed during the autumn and spring months $(8,55,56)$. Winter cough can become epidemic (56) - see the "cough of Perinthos' epidemic. Cough can be dry or productive, characterized by the production of sputum $(24,55,57)$ and can be combined with pleurodynia, respiratory distress, orthopnoea, gastrointestinal disorders, arthralgia and fever $(57,62)$. Cough associated with fever and pleurodynia is indicative of pneumonia (62). In cases with cough, the symptoms of 'violent' coughing, anorexia and arthralgia are also considered to be negative prognostic indicators proposing the presence of pneumonia with pleuritis or empyema (56). Cases of bacterial pneumonia, pleuritis and empyema appear frequently in the Hippocratic Corpus - we have not included their detailed references to bacterial infections since these are beyond the aims of the current review.

Different regimens for the management of children's cough and respiratory distress are recommended, included oral medications, inhalations and suppositories (32). Emphasis is given to the role of specific herbs, such as 'thapsia', - a poisonous herd in the Apiaceae family, which grows wild in the Western Mediterranean, and is thought to originate in ancient Thapsos in Sicily or Thapsa in the island of Evia - , which can be given mixed with barley flour for the management of cough in children (32). In the Books Nature of Man, On Regimen in Acute Diseases and On Women's I (24,28,32), we read about medications and remedies that produce sputum. The role of different diet components in the production of sputum, such as pomegranate juice, sesame, raisin, cheese, wine mixed with honey and olive oil, is also discussed in the Book On Affections (62).

The 'cough of Perinthos' epidemic. The 'cough of Perinthos' epidemic is an influenza-like outbreak, recorded in the Books Epidemics II, Epidemics IV, Epidemics VI and Epidemics VII $(52,54,56,57)$. It occurred in Perinthos, an ancient Greek seaside town on the Sea of Marmara, the inland sea, which connects the Black to the Aegean Sea. In the Book Epidemics VI (56), we read about the onset of cough during the winter 'on the 15 th or the 20th day after the winter solstice' of an unidentified year around the second half of the 5th century B.C. 'due to the frequent changes of the south winds, the north winds and the snowfalls'. This epidemic occurred during the winter and spring and involved both sexes and all ages, including children. The principal symptom of the outbreak was cough, while in several cases pneumonia was developed (56). Its course was usually benign, the 'crisis was easy' and the duration of the disease limited. However, after 40 days, several patients had a relapse and developed one or more of the following symptoms: Sore throat, dyskataposia, rigor, herpangina, fits of 'violent' coughing, dyspnoea, fatigue, otalgia, pain in the limbs, paralysis of the soft palate or of the limbs, disturbed vision, pain in the neck and the head, arthralgia on the 20th day and 'skin ulcers' on the lower limbs, that led to the 'crisis' of the disease $(54,56)$. The presence of 'pain in the neck and the head' was indicative of 'shoulder arthritis', that could lead to the development of 'galiangonas' $(54,56)$, a condition which is well described in the Book On Joints (49). Patients with disturbed vision, especially during the night, are mentioned in the Books Epidemics $I V$ and Epidemics VI $(54,56)$.

In the Book Epidemics VII (57), we meet several case reports of pneumonia, referring to the 'cough of Perinthos' epidemic; the outcome in several of these cases was fatal. For example, the child of Amfifradeos with pneumonia complication, presented pleuritic pain in the left ribs, cough and diarrhoea. The child became apyrexial on the 7th day, while coughing was predominating. On the 12 th day the child started producing 'yellowish sputum' and displayed respiratory distress, which was worsening; the child died on the 28th day (57).

Based on observation, Hippocrates tried impressively to detect prognostic factors for the course of the disease $(52,54,56)$. In patients working with the hands, paralysis occurred in the upper limbs, while those, who were walking excessively, in the lower limbs $(8,54,56)$. Children seemed to have more problems with seeing at night (56). Patients with specific underlying diseases, such as 'hydrop' (54) or 'phthisis' (56), referring to tuberculosis, had a worse clinical course of the disease. However, patients with other underlying diseases, such as nephritic disorders, were not affected or had a milder course of the disease $(52,56)$. Patients, who had fever, rigor and difficulty in breathing, were more likely to die, while others recovered, especially those who had dyskataposia (56).

Interestingly, several researchers have suggested that this outbreak of influenza-like symptoms is the first written description of an influenza epidemic, giving emphasis to the presence of fever, coughing and fatigue $(70,75)$. However, as the description refers to a mosaic of different symptoms that are difficult to be encompassed in only one illness, it is also possible that the outbreak included the simultaneous emergence of two or more infectious diseases, among them influenza, diphtheritis, whooping cough, polio, dengue fever and deficiency disorders, notably that of Vitamin A, which results in night blindness and can aggravate respiratory infections.

Otitis. The presence of effusion in ears, referring to otitis media with effusion, occurs very frequently in neonates and children, while earache, referring to external otitis, predominates during the summer months (8). In the Book Prognostics (9), we find the description of an abrupt onset of ear pain, the integral symptom of acute purulent otitis media, accompanied by fever, cough and irritability. This is usually a mild, self-controlled disease; however, it can become disabling, crippling and death-dealing. The presence of 'white pus' has also been described and it is well documented that 'when it runs from the ear, there may be hope that a younger person will recover'. Interestingly, in the Book Epidemics II (52), during his discussion of the "cough of Perinthos' epidemic, Hippocrates describes with impressive 
accuracy two untreated cases of acute purulent otitis media with membrane rupture, that of Zoile and Empedotimi. In both cases, the tympanic membrane was perforated, allowing the pus in the middle-ear space to drain into the ear canal. Another case, that of the daughter of Enmiris, with otitis media occurred during the 'cough of Perinthos' epidemic is also mentioned in the Book Epidemics IV (54). In Zoile, the membrane rupture occurred on the 8th to 9th day of the disease, in Empedotimi on the 9th day, while in the daughter of Enmiris on the 8th day $(52,54)$. In the Book Epidemics VI (56), we read that 'ruptures of the ears' occur on the 5th day or earlier. In all cases, the membrane rupture leads to earache relief $(52,57)$.

It is also well documented that otitis may be associated with hearing loss affecting the child's ability to learn (59). In the Book Epidemics $V$, we read about the management of Parmeniskos' child, who developed hearing loss, possibly as a result of otitis media (55). The same case report also reappears in the Book Epidemics VII (57), where additional information on the recommended diet was included; the precise cause of hearing loss in both references is not mentioned.

What is perhaps the most striking complication of acute purulent otitis media in the Hippocratic Corpus is discussed in the Book Epidemics VII (57), where we find the case report of Cydis' son. In the thorough description of this case, which suggests the diagnosis of meningoencephalitis secondary to otitis, the child exhibited a suppurative ear discharge with fever, headache, vomiting, mental confusion and intense neck rigidity. A similar complication of encephalitis secondary to otitis is assumed in the description of encephalitis accompanied by tympanic rupture in the Book On Diseases III (60).

For the management of earache, there are detailed Hippocratic recommendations, including the use of milk as well as the performance of 'suction cupping' $(52,62)$. Moreover, these are accompanied by his criticisms of the practices followed by other physicians at that time for the management of otalgia (56).

Meningoencephalitis. The Hippocratic Corpus frequently refers to patients, including children, who suffered from

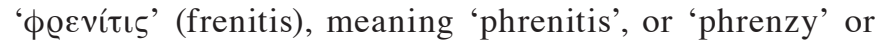
who were 'phrenitic' or developed 'phrenitic paroxysms' $(9,12,17,51,53,58,60,62,63)$. 'Phrenitis' occurs more commonly during the winter months $(51,62)$. Its course is acute; its outcome is usually fatal, while some cases survive $(9,12,51,58,60,62)$. It also seems that the pathophysiology of meningoencephalitis was well known at that time. In the Book On Diseases III (60), we find an impressive description of the oedema presented in encephalitis, which can be accompanied by either generalized or local inflammation. In the Book On Diseases II (59), Hippocrates writes of 'water on the brain', referring to hydrocephalus or dropsy, which can be acute or chronic. Interestingly, in the Book On Diseases I (58), we find a proposed theory about the pathophysiology of fatal 'phrenitis'.

'Phrenitis' is presented with fever, headache, convulsions and coma $(51,53)$. The co-presence of headache and fever with 'death-leading' signs is dangerous for the patient (9). Nuchal rigidity and opisthotonus, occurring when the posterior tendons of the neck are affected, are well-described signs of menigism $(12,17,63)$. Nuchal rigidity is also proposed as a negative prognostic factor in the case of fever (12). In the Book Epidemics I (51), Hippocrates describes cases of 'phren- itic' patients, who displayed pain and heaviness on the head and neck, with or without fever, convulsions and aeruginous vomiting. Interestingly, children were 'generally attacked' and several cases were fatal. In the Book Epidemics III (53), we read about an outbreak of cases of 'phrenitis' and fever, which occurred early in the spring with fatal outcome in most of the cases. In the same Book (53), a case of 'phrenzy' was described. The patient suffered from a heavy feeling and pain in the head and neck, with fever and convulsions at night. These symptoms were more severe on the 3rd day, and on the 4th day, the patient died. In the Book Epidemics VII (57), we find the case report of the Timonaktos' child, who 'for two months had rashes on the legs, hips, back and abdomen accompanied by red swelling'. When the rash resolved, the child 'presented with convulsions and epileptic phenomena without fever that lasted for days and then the child died'.

'Phrenitis' accompanied by fever can be either primary or secondary, due to other diseases or inflammations (60). An example of meningoencephalitis secondary to otitis media is given in the Book Epidemics VII (57). In this reference, we find the case report of Cydis' son, who exhibited a suppurative ear discharge with fever, headache, vomiting, mental confusion and intense neck rigidity. Moreover, in the Books On Critical Days and On Internal Affections (17,63), we read that opisthotonos, a sign of menigism, can be caused by herpangina, inflammation of the palatine uvula and purulent tonsilitis.

In the Books On Diseases II and On Diseases III $(59,60)$, we find the term ' $\sigma \phi \alpha x \varepsilon \lambda \iota \sigma \mu o ̀ s ~ \dot{\varepsilon} \gamma x \varepsilon \phi \alpha ́ \lambda$ ov' (sfakelismos egkefalou), referring to cases with severe encephalitis accompanied by fever. This disease is acute and its outcome is fatal, usually in 3-5 days $(8,59)$. In the Book On Diseases II (59), another

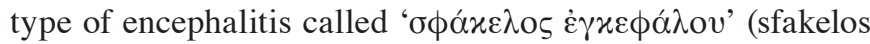
egkefalou), accompanied by fever and rigor, was managed with 'cranial anatresis' leading to 'iasis'. 'Cranial anatresis' is a well-known surgical procedure, described in the Book On Head Injuries (43), with fully-defined complications that are also mentioned in detail $(43,55,57)$.

In several sites $(12,51,55,56)$ of the Hippocratic Corpus, we also come across several terms used in order to describe delirium, paresthesia, speech disorders and coma symptom-

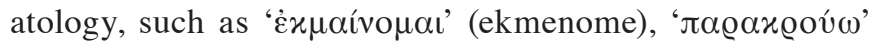
(parakrouo), ' $\pi \alpha \varrho \alpha \lambda \eta \varrho \omega ́$ (paraliro), ' $\lambda \hat{\eta} \varrho o \varsigma '$ (liros), ' $\pi \alpha \varrho \alpha \phi \varrho o v \omega ́$ ' (parafrono), ' $\pi \alpha \varrho \alpha x o ́ \pi \tau \omega '$ (parakopto) and ' $x \omega \mu \alpha \tau \omega ́ \delta \varepsilon \varepsilon \varsigma$ ' (comatodees). However, the precise usage of each term is not clear; moreover, it is difficult to differentiate in these cases whether the described conditions include meningoencephalitis, secondary meningoencephitis due to pneumonia or other infections, or other neurological disorders, occurring in adults, such as ischaemic attacks.

Hippocrates is really impressed by specialized physicians, who try to manage meningoencephalitis, as this is a disease with a fatal outcome (28). In the Book On Regimen in Acute Diseases (28), we read that the physicians, who are superior in the treatment of fatal diseases, such as meningoencephalitis, deserve his 'compliments'. This undoubtedly is a primitive reference to the value of Neonatal and Paediatric Intensive Care Medicine, which nowadays offer advanced life support, management and treatment of severe viral infectious diseases in neonates and children. 
Febrile convulsions. Febrile convulsions, which usually occur at the onset or during viral infections in childhood, are described well $(8,9,12,41,51)$ in the Hippocratic Corpus. In the Books Prognostics and Coan Prenotions $(9,12)$, we read that in childhood the acute onset of fever can lead to febrile convulsions. These usually are initiated after the age of 6 months, when teething begins (8), and occur up to the age of 7 years (9). Febrile convulsions are usually benign, unless there is an underlying coexisting disease, with negative prognosis $(12,41,51)$.

Although no other information or comments on potential viral infections associated with febrile convulsions are found, the accurate key-message description of this common benign condition in childhood is really impressive. Moreover, it is well differentiated from meningoencephalitis, which was presented in the previous section.

Gastroenteritis. Gastroenteritis - termed 'dysenteritis' - is defined as the inflammation of the intestine characterized by the presence of diarrhoea, a common condition of having frequent loose or liquid bowel movements $(8,57)$. The term ' $\delta$ ı́o@oı $\alpha$ ' (diarrhoea) derives from 'oı $\alpha$ ' (dia), meaning 'through', and '@̣é $\omega$ ' (rheo), meaning 'flow'. In some cases, 'dysenterititis' is accompanied by haemorrhagic stools, as well as by mucous $(55,62)$. The usage of the term 'dysenteritis' does not imply any presence of blood visible in stools, like the modern definition (8). In the Hippocratic Corpus, we also come across the term 'lientery', describing a form of diarrhoea, in which food passes through the body with little or no digestion $(8,51,53,62)$. This term is used to describe a gastrointestinal condition similar to 'dysenteritis', requiring a similar management approach $(8,62)$.

Other recognized symptoms of gastroenteritis include lower abdominal pain, anorexia, vomiting, reflux and tenesmus $(52,54,62)$. Gastroenteritis can be presented with or without fever (11). In infants the presence of fever and diarrhoea can be commonly accompanied by lethargy (41). Gastroenteritis can be combined with dehydration, demonstrated by a dry tongue (57). Dehydration is a well-described condition, which can also be the result of fever, leading to death (58). Moreover, febrile gastroenteritis can be fatal, especially in children from ages 5 to 10 years (10). Febrile gastroenteritis, which is accompanied by anorexia, is associated with negative prognosis (56). The presence of acute gastroenteritis in cases with splenomegaly is milder, while chronic gastroenteritis in cases with splenomegaly can be fatal (8).

Gastroenteritis predominates during the summer months $(8,13,51,57)$; however, it can also occur during autumn (51) as well as spring (24). It is usually a benign, self-treated disease and its duration is limited; however, in some cases it can become chronic, while it can also have fatal outcome $(11,58)$. Despite no reference to the different causes of gastroenteritis being mentioned, 'dysenteritis' is differentiated from 'cholera' $(27,55,57)$ and different types of 'typhus' $(54,63)$.

The initial principle for the management of gastroenteritis in children is found in the Book Aphorisms (8), where we read that the presentation of diarrhoea and vomiting are 'useful' for the 'catharsis' of the patient with gastroenteritis. This principle, proposing diarrhoea and vomiting as an evolved expulsion defense mechanism, makes clear that these symptoms should not be deranged. This principle is also found in the Book
Epidemics VII (57), where it is explained that the 'catharsis' at the initial stages of several diseases should be automatic and not iatrogenic.

The role of the early onset of the management of vomiting is also highlighted for the prevention of dehydration (27). In the Books Aphorisms and Epidemics II $(8,52)$, the need for rehydration in case of fever and vomiting is highlighted. Different regimes, as well as diet components, such as apple juice, which can be used in cases of children's vomiting, are recommended $(27,58)$. The significant role of diet, exercise, as well as different regimes, containing for example cooked beans, is also recognized for the management of diarrhoea in cases of gastroenteritis $(27,28,32,52)$. In the Book Epidemics $V(55)$, we detect the case report of an 'adolescent, who came from the island of Evia' with gastroenteritis, which was managed incorrectly, leading to death (55). Although no further detailed information on this case is found, this could definitely be an example of mismanagement that Hippocrates gives in order to highlight it to his colleagues. The descriptions of similar cases of maltreatment with relevant Hippocratic criticism are also found in the Books Epidemics V and Epidemics VI $(55,56)$.

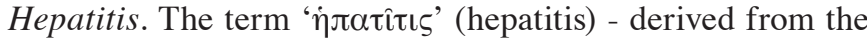
ancient Greek iं $\pi \alpha \varrho$ (hepar), meaning 'liver', and the suffix '-îtı૬' (-itis), meaning 'inflammation' - is used in the Book On Internal Affections (63), in the three relevant sections on the diseases of the liver. Hepatitis 'arises from the dark bile, when it flows to the liver'. 'It attacks in autumn during the change of the year', it says. The patients with hepatitis suffer from 'sharp pain at the liver area, the lower ribs, the shoulder, the clavicle and the chest'. There is 'violent choking' and sometimes the patient vomits 'livid bile'. Rigor and fever, intense during the first days, but milder afterwards, set in (63). Sometimes the onset of the disease is acute; hepatitis can become chronic and in some cases fatal $(58,63)$. The pathophysiology of hepatitis, as well as its accompanied symptoms, such as jaundice, dropsy, pale and foul-smelling stools, fever, itching, rumbling of the intestine and upper abdominal pain, are well described $(58,63)$. Detailed recommendations on the management of pain, the need to have the patient abstain from foods until the disease reaches its 'crisis', as well as the gradual restart of feeding and diet instructions are given (63).

In the Book On Internal Affections (63), we also meet detailed references to several forms of jaundice, including 'epidemic jaundice', which undoubtedly is typical of viral hepatitis and refers to the infection caused by different hepatotropic viruses, such as the hepatitis B virus. Moreover, in the Book Aphorisms (8), we read that 'jaundice accompanied by diarrhoea is usually more benign than other forms', thus reminding us of the case of hepatitis A virus infection among children. In the Books Epidemics II, On Diseases II and On Affections $(52,59,62)$, we also read about different forms of jaundice, its management and its prognosis. Jaundice 'developed on the sixth day' was one of the recorded signs of an epidemic disease in the island of Thasos (Third Constitution) described in the Book Epidemics I (51).

Poliomyelitis. In the Book Epidemics I (51), in the begging of the Third Constitution, we find a reference to a severe paralytic disease, which occurred during the winter months on the island 
of Thasos. The term used was ' $\pi \alpha \varrho \alpha \pi \lambda \eta \gamma$ í $\iota^{\prime}$ ' (parapligiai), meaning 'paraglegia', and it is clearly stated that there was an increased prevalence constituting an epidemic, as well as a significant mortality due to the disease. Although this epidemic was linked to the winter rather than the summer or autumn seasons - referred to as the polio period - this condition can still be attributed to a poliomyelitis epidemic. Of note, the accurate term 'poliomyelitis' used to describe the effect of poliovirus on the spinal cord - derived from the ancient Greek words for

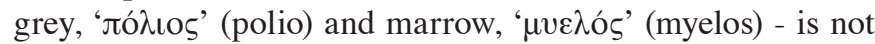
Hippocratic, but was coined in 1874 by Adolph Kussmaul (76).

Moreover, there are also several descriptions of crippling conditions, some of which may have been attributable to poliovirus $(10,52,54)$. In the Book Epidemics II (52), the case of a little girl with right hand and left foot paralysis is described. In the Book Epidemics IV (54), two more cases of paralysis are discussed: a child, who was working in a vineyard, and Amyntas' son, who had right-hand paralysis, while in other cases paralysis was observed in the loin and the lower limbs. These cases occurred during the 'cough of Perinthos' epidemic. Cases of paraglegia, which occurred during the 'cough of Perinthos' epidemic, are also mentioned in the Book Epidemics VI (56). In the Book Prorrhetics I (10), there is also a reference to a fatal case of apoplexy accompanied by fever - the case of Noumenios' son. However, the final diagnosis of these cases is not clear.

\section{Conclusion}

Hippocrates does not confine himself to philosophical statements and general recommendations about the art of Medicine. His study, which embodies the clinical practice of the second half of the 5th century B.C., has a unique historical value as it presents $>18$ different viral infections common in neonates and children. Moreover, his approach towards the diseases he discusses is methodologically rigorous and systematic, and this is encountered perhaps for the first time in the history of Medicine. Medical principles, observational data and therapeutic knowledge on viral infections in neonates and children are documented in great detail and are critically evaluated. Undoubtedly, this study can be used in subspecialty training in Paediatric Virology and can enthusiastically inspire current paediatric trainees, as well as future Paediatric Virology subspecialtists (69).

\section{Acknowledgements}

The authors gratefully acknowledge the chairpersons of the 'Workshop on Paediatric Virology' held in Athens, Greece, on the 10th October, 2015, Professor Anne Greenough, Professor of Neonatology and Clinical Respiratory Physiology at King's College in London (UK) and Vice-President of the Royal College of Paediatrics and Child Health (RCPCH), Professor Anna Kramvis, Research Professor of Molecular Virology and Director of the Hepatitis Virus Diversity Research Unit of the University of the Witwatersrand in Johannesburg (South Africa) and Professor Maria Theodoridou, Professor of Paediatric Infectious Diseases at the 'Aghia Sophia' Children's Hospital in Athens (Greece) as well as all members of the Paediatric Virology Study Group (PVSG) for their comments and support. The authors would also like to thank Dr. Anastasia Stouraiti (Goldsmiths University of London, London, UK), Alexander Kazamias (Coventry University, Coventry, UK), Melpomeni Kountouri (University of Birmingham School of Medicine, Birmingham, UK) and Fergus Maher (University of Liverpool School of Medicine, Liverpool, UK) for reviewing this manuscript.

\section{References}

1. Hippocrates: Oath (Orkos). In: Hippocrates, Apanta 1. Cactus Editions, Athens, 1993 (In Greek).

2. Hippocrates: Law (Nomos). In: Hippocrates, Apanta 1. Cactus Editions, Athens, 1993 (In Greek).

3. Hippocrates: On Ancient Medicine (Peri Arhaiis Iitrikis). In: Hippocrates, Apanta 1. Cactus Editions, Athens, 1993 (In Greek).

4. Hippocrates: On Physician (Peri Iitrou). In: Hippocrates, Apanta 1. Cactus Editions, Athens, 1993 (In Greek).

5. Hippocrates: On Art (Peri Tehnis). In: Hippocrates, Apanta 1. Cactus Editions, Athens, 1993 (In Greek).

6. Hippocrates: On Physician's Establishment (Peri eushimosinis) In: Hippocrates, Apanta 1. Cactus Editions, Athens, 1993 (In Greek).

7. Hippocrates: Precepts (Paraggeliai). In: Hippocrates, Apanta 1. Cactus Editions, Athens, 1993 (In Greek).

8. Hippocrates: Aphorisms (Aforismoi). In: Hippocrates, Apanta 1. Cactus Editions, Athens, 1993 (In Greek).

9. Hippocrates: Prognostics (Prognostikon). In: Hippocrates, Apanta 2. Cactus Editions, Athens, 1993 (In Greek)

10. Hippocrates: Prorrhetics I (Prorritikos A). In: Hippocrates, Apanta 2. Cactus Editions, Athens, 1993 (In Greek).

11. Hippocrates: Prorrhetics II (Prorritikos B). In: Hippocrates, Apanta 2. Cactus Editions, Athens, 1993 (In Greek).

12. Hippocrates: Coan Prenotions (Coakai Prognosies). In: Hippocrates, Apanta 2. Cactus Editions, Athens, 1993 (In Greek).

13. Hippocrates: On Airs, Waters, Places (Peri Aeron, Ydaton, Topon). In: Hippocrates, Apanta 3. Cactus Editions, Athens, 1993 (In Greek).

14. Hippocrates: On Humors (Peri Hymon). In: Hippocrates, Apanta 3. Cactus Editions, Athens, 1993 (In Greek).

15. Hippocrates: On Airs (Peri Fyson). In: Hippocrates, Apanta 3. Cactus Editions, Athens, 1993 (In Greek).

16. Hippocrates: On Crises (Peri Krision). In: Hippocrates, Apanta 3. Cactus Editions, Athens, 1993 (In Greek)

17. Hippocrates: On Critical Days (Peri Krisimon). In: Hippocrates, Apanta 3. Cactus Editions, Athens, 1993 (In Greek).

18. Hippocrates: On Vision (Peri Opsios). In: Hippocrates, Apanta 3. Cactus Editions, Athens, 1993 (In Greek).

19. Hippocrates: On Anatomy (Peri Anatomis). In: Hippocrates, Apanta 4. Cactus Editions, Athens, 1993 (In Greek).

20. Hippocrates: On Heart (Peri Kardiis). In: Hippocrates, Apanta 4. Cactus Editions, Athens, 1993 (In Greek).

21. Hippocrates: On Glands (Peri Adenon). In: Hippocrates, Apanta 4. Cactus Editions, Athens, 1993 (In Greek).

22. Hippocrates: On Fleshes (Peri Sarkon). In: Hippocrates, Apanta 4. Cactus Editions, Athens, 1993 (In Greek).

23. Hippocrates: On Nature of Bones (Peri Osteon Fysios). In: Hippocrates, Apanta 4. Cactus Editions, Athens, 1993 (In Greek).

24. Hippocrates: On Nature of Man (Peri Fysios Anthropou). In: Hippocrates, Apanta 4. Cactus Editions, Athens, 1993 (In Greek).

25. Hippocrates: On Semen (Peri Gonis). In: Hippocrates, Apanta 4. Cactus Editions, Athens, 1993 (In Greek).

26. Hippocrates: On Nature of Child (Peri Fysios Paidiou). In: Hippocrates, Apanta 4. Cactus Editions, Athens, 1993 (In Greek).

27. Hippocrates: On Regimen (Peri Diaitis). In: Hippocrates, Apanta 5. Cactus Editions, Athens, 1993 (In Greek).

28. Hippocrates: On Regimen in Acute Diseases (Peri Diaitis Okseon). In: Hippocrates, Apanta 6. Cactus Editions, Athens, 1993 (In Greek).

29. Hippocrates: On Regimen in Health (Peri Diaitis Ygieinis). In: Hippocrates, Apanta 6. Cactus Editions, Athens, 1993 (In Greek).

30. Hippocrates: On Aliment (Peri Trofis). In: Hippocrates, Apanta 6. Cactus Editions, Athens, 1993 (In Greek).

31. Hippocrates: On Use of Liquids (Peri Ygron Hrisios). In: Hippocrates, Apanta 6. Cactus Editions, Athens, 1993 (In Greek).

32. Hippocrates: On Women's I (Peri Gynaikeion Proton). In: Hippocrates, Apanta 7. Cactus Editions, 1993 (In Greek). 
33. Hippocrates: On Women's II (Peri Gynaikeion Deuteron). In: Hippocrates, Apanta 8. Cactus Editions, Athens, 1993 (In Greek).

34. Hippocrates: On Nature of Women (Peri Gynaikeiis Fysios). In: Hippocrates, Apanta 9. Cactus Editions, Athens, 1993 (In Greek).

35. Hippocrates: On Sterile Women (Peri Aforon). In: Hippocrates, Apanta 9. Cactus Editions, Athens, 1993 (In Greek).

36. Hippocrates: On Diseases of Girls (Peri Parthenion). In: Hippocrates, Apanta 9. Cactus Editions, Athens, 1993 (In Greek)

37. Hippocrates: On Superfoetation (Peri Epikyiseos). In Hippocrates, Apanta 10. Cactus Editions, Athens, 1993 (In Greek).

38. Hippocrates: On Excision of Foetus (Peri Egkatatomis Embriou). In: Hippocrates, Apanta 10. Cactus Editions, Athens, 1993 (In Greek)

39. Hippocrates: On Seventh Month's Foetus (Peri Eptaminou). In: Hippocrates, Apanta 10. Cactus Editions, Athens, 1993 (In Greek).

40. Hippocrates: On Eighth Month's Foetus (Peri Oktaminou). In: Hippocrates, Apanta 10. Cactus Editions, Athens, 1993 (In Greek).

41. Hippocrates: On Dentition (Peri Odontofyiis). In: Hippocrates, Apanta 10. Cactus Editions, Athens, 1993 (In Greek).

42. Hippocrates: On Weeks (Peri Ebdomadon). In: Hippocrates, Apanta 10. Cactus Editions, Athens, 1993 (In Greek).

43. Hippocrates: On Head Injuries (Peri ton en Kefali Tromaton) In: Hippocrates, Apanta 11. Cactus Editions, Athens, 1993 (In Greek).

44. Hippocrates: On Surgery (Kat' Iatreion). In: Hippocrates, Apanta 11. Cactus Editions, Athens, 1993 (In Greek).

45. Hippocrates: On Fractures (Peri Agmon), Apanta 11. Cactus Editions, Athens, 1993 (In Greek).

46. Hippocrates: On Ulcers (Peri Elkon). In: Hippocrates, Apanta 11 Cactus Editions, Athens, 1993 (In Greek).

47. Hippocrates: On Hemorrhoids (Peri Aimorroidon). In: Hippocrates, Apanta 11. Cactus Editions, Athens, 1993 (In Greek).

48. Hippocrates: On Fistulae (Peri Syriggon). In: Hippocrates, Apanta 11. Cactus Editions, Athens, 1993 (In Greek).

49. Hippocrates: On Joints (Peri Arthon). In: Hippocrates, Apanta 12. Cactus Editions, Athens, 1993 (In Greek).

50. Hippocrates: On Instruments of Reduction (Mohlikon) In: Hippocrates, Apanta 12. Cactus Editions, Athens, 1993 (In Greek).

51. Hippocrates: Epidemics I (Epidemion to Proton). In: Hippocrates, Apanta 13. Cactus Editions, Athens, 1993 (In Greek).

52. Hippocrates: Epidemics II (Epidemion to Deuteron). In: Hippocrates, Apanta 13. Cactus Editions, Athens, 1993 (In Greek)

53. Hippocrates: Epidemics III(Epidemion to Triton).In: Hippocrates, Apanta 13. Cactus Editions, Athens, 1993 (In Greek).

54. Hippocrates: Epidemics IV (Epidemion to Tetarton). In: Hippocrates, Apanta 14. Cactus Editions, Athens, 1993 (In Greek).

55. Hippocrates: Epidemics V (Epidemion to Pempton). In: Hippocrates, Apanta 14. Cactus Editions, Athens, 1993 (In Greek)

56. Hippocrates:Epidemics VI(Epidemion toEkton).In:Hippocrates, Apanta 14. Cactus Editions, Athens, 1993 (In Greek).

57. Hippocrates: Epidemics VII (Epidemion to Ebdomon). In: Hippocrates, Apanta 14. Cactus Editions, Athens, 1993 (In Greek).
58. Hippocrates: On Diseases I (Peri Nouson to Proton). In Hippocrates, Apanta 15. Cactus Editions, Athens, 1993 (In Greek)

59. Hippocrates: On Diseases II (Peri Nouson to Deuteron). In: Hippocrates, Apanta 15. Cactus Editions, Athens, 1993 (In Greek)

60. Hippocrates: On Diseases III (Peri Nouson to Triton). In: Hippocrates, Apanta 15. Cactus Editions, Athens, 1993 (In Greek).

61. Hippocrates: On Diseases IV (Peri Nouson to Tetarton). In: Hippocrates, Apanta 15. Cactus Editions, Athens, 1993 (In Greek).

62. Hippocrates: On Affections (Peri Pathon). In: Hippocrates, Apanta 16. Cactus Editions, Athens, 1993 (In Greek).

63. Hippocrates: On Internal Affections (Peri ton Entos Pathon) In: Hippocrates, Apanta 16. Cactus Editions, Athens, 1993 (In Greek).

64. Hippocrates: On Sacred Disease (Peri Ieris Nousou). In: Hippocrates, Apanta 16. Cactus Editions, Athens, 1993 (In Greek).

65. Hippocrates: On Places in Man (Peri Topon ton kata Anthropon). In: Hippocrates, Apanta 16. Cactus Editions, Athens, 1993 (In Greek).

66. Mammas IN and Spandidos DA: Four historic legends in human papillomaviruses research. J BUON 20: 658-661, 2015.

67. Mammas IN and Spandidos DA: An instructive viewpoint from the Greek mythology. J Paediatr Child Health 51: 172-173, 2015.

68. Mammas IN, Greenough A, Theodoridou M and Spandidos DA Paediatric Virology: A new paediatric subspecialty? A proposal at the Workshop on Paediatric Virology, Athens, October 10 2015. Exp Ther Med 11: 3-5, 2016.

69. Mammas IN, Greenough A, Theodoridou M, Kramvis A, Christaki I, Koutsaftiki C, Koutsaki M, Portaliou DM, Kostagianni G, Panagopoulou P, et al: Current views and advances on Paediatric Virology: An update for paediatric trainees. Exp Ther Med 11: 6-14, 2016.

70. Pappas G, Kiriaze IJ and Falagas ME: Insights into infectious disease in the era of Hippocrates. Int J Infect Dis 12: 347-350, 2008.

71. Falagas ME, Bliziotis IA, Kosmidis J and Daikos GK: Unusual climatic conditions and infectious diseases: Observations made by Hippocrates. Enferm Infecc Microbiol Clin 28: 716-718, 2010.

72. Tsoucalas G, Laios K, Karamanou M and Androutsos G: The Thasian epidemic of mumps during the 5th century BC. Infez Med 21: 149-150, 2013.

73. Beswick TSL: The origin and the use of the word herpes. Med Hist 6: 214-232, 1962

74. Sgantzos M, Tsoucalas G, Karamanou M, Giatsiou S, Tsoukalas I and Androutsos G: Hippocrates on Pediatric Dermatology. Pediatr Dermatol 32: 600-603, 2015.

75. Kohn GC: Cough of Perinthus. In: Encyclopedia of Plague and Pestilence: from ancient times to the present. 3rd edition. Facts on File, Inc., New York, NY, 2008.

76. Smallman-Raynor MR, Cliff AD, Trevelyan B, Nettleton C and Sneddon S: Poliomyelitis. A world geography: emergence to eradication. Oxford University Press, New York, NY, 2006. 